\title{
Isolation and Identification of Mannheimia haemolytica and Pasteurella multocida Species from Ruminants in Six Different Regions in Morocco
}

\author{
Ghizlane Sebbar ${ }^{1,2}$, Khalil Zro ${ }^{1}$, Faouzi Kichou ${ }^{3}$, Abdelkrim Fillali Maltouf ${ }^{2}$ and Bouchra Belkadi ${ }^{2}$ \\ 1. Society of Veterinary Pharmaceutical and Biological Productions (Biopharma), B.P. 4569, Rabat, Morocco \\ 2. Laboratory of Microbiology and Molecular Biology, Faculty of Sciences, University Mohammed V, 4 Ibn Battouta Ave. BP 1014 \\ RP Rabat, Morocco
}

3. Institute of Agronomy and Veterinary Medicine Hassan II, B.P. 6202, Rabat, Morocco

\begin{abstract}
Pasteurella species is considered the principal pathogen of the respiratory tract. Mannheimia haemolytica and Pasteurella multocida were investigated and typed from nasal swabs and tissues taken from sheep, goat and cattle. Indeed, 41 lung and 121 nasal swabs samples were collected from animals with respiratory diseases during 2015 to 2017 in six different regions in Morocco. At first, a screening of Pasteurella species using the real time PCR (RT-PCR) was carried out, then all isolated strains on agar blood were confirmed by PCR gel based assay specific for M. haemolytica and P. multocida. Pathogenicity was evaluated in mice and histopathological examination was done on some of lung tissue. The results revealed that 34 samples of which 28 (55\%) from nasal swabs and six (38\%) from lungs were positive for M. haemolytica and nine samples of which seven (14\%) from nasal swabs and two (13\%) from lungs were positive on P. multocida serogroup A. Seventy-two percent (72\%) isolates were highly pathogenic to mice, which is in accordance with the results obtained by histopathology examination. This is the first report for widespread infections of Pasteurella (M. haemolytica \& P. multocida) in ruminants in Morocco. Therefore, measures including development of vaccines are highly required to mitigate the impact of the bacteria in animals.
\end{abstract}

Key words: Isolation, identification, PCR, Mannheimia haemolytica, Pasteurella multocida, histopathology, Morocco.

\section{Introduction}

Pasteurellosis is a febrile and contagious respiratory disease common to a large of ruminants. Clinically, the infection is characterized by very severe general symptoms [1] causing death in a few hours and most often associated with severe bronchopneumonia and enlargement of respiratory lymph nodes and systemic haemorrhagic and/or oedematous lesions. There have been several denominations for the disease, including enzootic pneumonia, enzootic broncho-pneumonia and haemorrhagic septicaemia (in young animals). Pasteurella spp has been recognised as the bacterium responsible for this infection. It belongs to the super

Corresponding author: Ghizlane Sebbar, Ph.D. student, research fields: microbiology and molecular biology. kingdom of bacteria, phylum of proteobacteria, class of gammaproteobacteria, pasteurellales order, family of Pasteurellaceae and the genus Pasteurella [2]. Mannheimia haemolytica and P. multocida are the most common etiological agents causing the disease characterized by high morbidity and mortality rates as well as severe economic losses [3-5].

The isolation of bacteria from blood, swabs and tissues of infected animals is the gold standard technique for diagnosis of pasteurellosis. The bacteriological differential diagnosis is based on Gram-staining, growth on blood agar and growth characteristics of pink to red colonies on MacConkey agar [6]. Moreover, hemagglutination, co-agglutination, counter immune-electrophoresis and immune-diffusion tests are also useful for 

Species from Ruminants in Six Different Regions in Morocco

confirmatory diagnosis. More recently, molecular techniques, including pulsed field gel electrophoresis, southern blots and polymerase chain reaction (PCR)-based assays are used to differentiate between capsular and somatic serotypes of Pasteurella. The PCR techniques are most likely used in endemic areas and can be used with various samples or bacterial cultures. Recently the quantitative real time PCR (RT-PCR) has been developed which is highly sensitive, specific and rapid [7].

In Morocco, little, if any, is reported about the prevalence and economic impact of Pasteurella in ruminants. Thus, the aim of this work was to determine for the first time the importance and impact of Pasteurella infection in clinically ill ruminants in Morocco.

\section{Materials and Methods}

\subsection{Sample Collection and Preparation}

A total of 162 samples were collected from different species of ruminants ( 76 bovine, seven goats and 79 sheep) including 121 nasal swabs from animals with signs of respiratory distress and 41 lung tissue samples from dead animals with characteristic respiratory macroscopic changes (congestion, edema, multifocal red and grey hepatisation of lungs and fibrin deposit on lung and pleural surfaces). The survey was conducted from 2015 to 2017 in six different regions of Morocco (Fig. 1). Lung samples were stored in sterile bags and nasal swabs in sterile gel friendly medium and were transported to Biopharma laboratory in appropriate conditions $\left(0-4{ }^{\circ} \mathrm{C}\right)$ within $6 \mathrm{~h}$. Lung tissues with macroscopic changes were sampled from 10 animals (six bovines and four sheep) and fixed in 10\% neutral-buffered formalin (NBF) for histopathological investigations.

Pre-enrichment of nasal swabs in brain heart infusion (BHI) broth was performed immediately after sample collection and proceeded for incubation at $37^{\circ} \mathrm{C}$ overnight according to Refs. [8,9]. Specimen

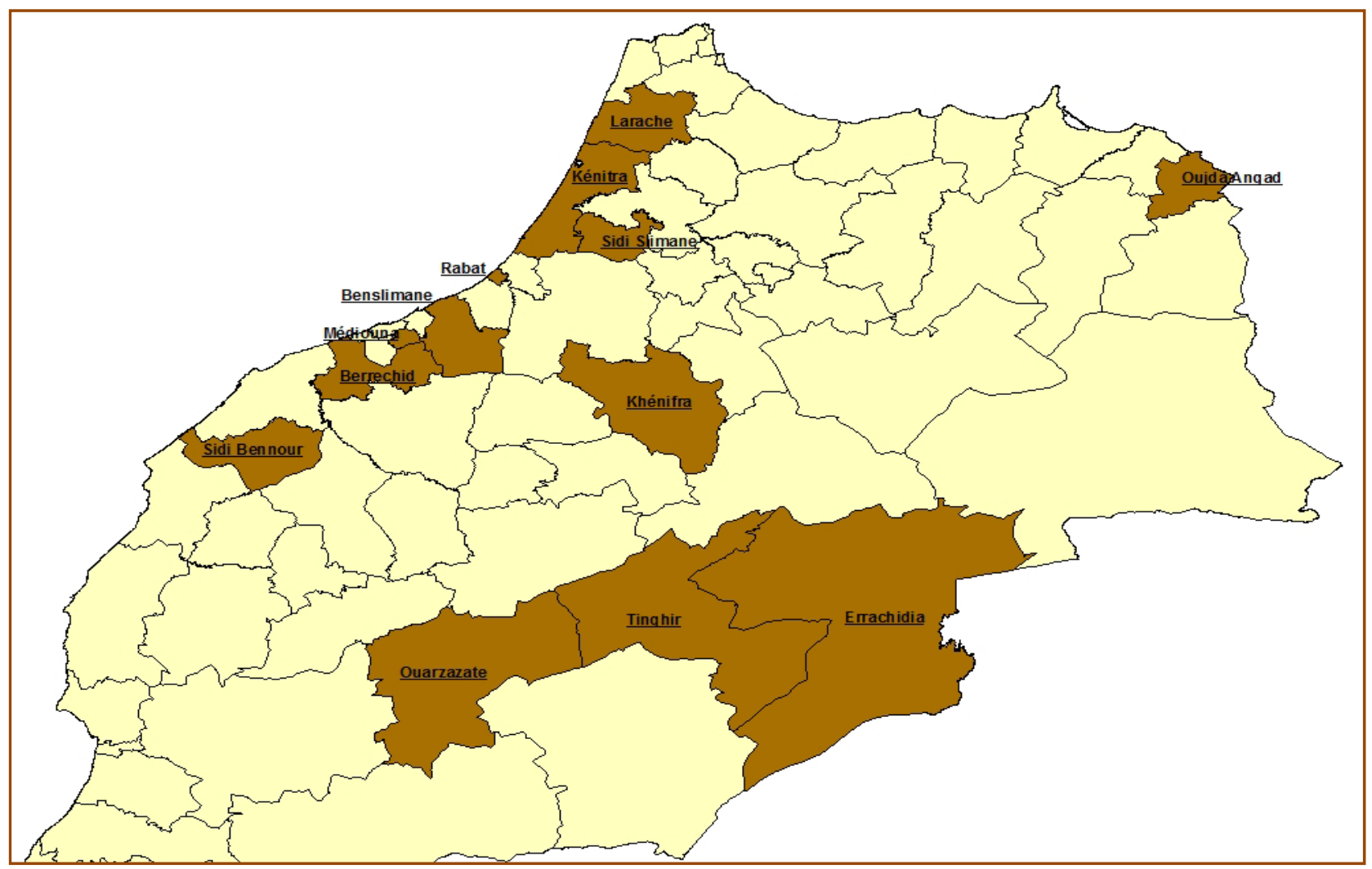

Fig. 1 Geographical distribution of samples collected from six different regions in Morocco in this study. 
from lungs were homogenized using an automatic grinder instrument (Bertin Technologies, France). The tissue suspensions were centrifuged at $8,000 \times \mathrm{g}$ for 10 min at $4{ }^{\circ} \mathrm{C}$ and were enriched in BHI overnight as described above.

\subsection{RT-PCR Screening}

Extraction of bacterial DNA from the overnight cultures (from swabs and lungs) was performed using the NucleoSpin Tissue Kit (Machery-Nagel, Germany) according to the manufacturer's instructions. RT-PCR was carried out using the TaqVet $^{\mathrm{TM}}$ triplex $P$. multocida \& M. haemolytica Kit (Life Technologies, USA) following the producer recommendations. A total of $5 \mu \mathrm{L}$ DNA was used in a total reaction volume of $20 \mu \mathrm{L}$. The assay was carried out on Smartcycler (Cepheid, USA) according to the following cycling profile: DNA polymerase activation $95{ }^{\circ} \mathrm{C}$ for $15 \mathrm{~min}$ followed by 45 cycles of amplification $\left(94{ }^{\circ} \mathrm{C}\right.$ for 1 min and $60^{\circ} \mathrm{C}$ for $1 \mathrm{~min}$ and $5 \mathrm{~s}$ ).

\subsection{Bacterial Isolation}

The positive samples by the RT-PCR were subjected to blood agar culturing $[8,9]$. The colonies suggestive of Pasteurella were subjected to Gram-staining, catalase and oxidase test and growth on MacConkey agar for further identification [10].

The molecular confirmation of Pasteurella species was performed using conventional PCR with specific primers targeting sodA gene fragment [11]. SodA gene encode the manganese-dependent superoxide dismutase (Mn-SOD); this gene has been proven to be a powerful target for differentiating related species within the Mannheimia and Pasteurella [12]. PCR reaction for $M$. haemolytica was performed in a total volume $25 \mu \mathrm{L}$ containing $0.1 \mu \mathrm{M}$ from each primer, $10 \mathrm{mM}$ dNTPs, $10 \times$ PCR buffer, $50 \mathrm{mM} \mathrm{MgCl} 2,5$ $\mathrm{U} / \mu \mathrm{L}$ from Taq DNA polymerase and $5 \mu \mathrm{L}$ from the isolated DNA. All reagents were supplied by Invitrogen. Taq DNA polymerase recombinant was purchased from Life Technologies, USA. The DNA was amplified under the following conditions in TC512 thermocycler (Techne, USA): a primary denaturation step at $94{ }^{\circ} \mathrm{C}$ for $3 \mathrm{~min}, 35$ cycles using the following settings: initial denaturation at $94{ }^{\circ} \mathrm{C}$ for $45 \mathrm{~s}$, annealing at $64{ }^{\circ} \mathrm{C}$ for $30 \mathrm{~s}$ and extension at $72{ }^{\circ} \mathrm{C}$ for $90 \mathrm{~s}$, followed by $10 \mathrm{~min}$ at $72{ }^{\circ} \mathrm{C}$.

PCR assay for P. multocida was confirmed by the same test with specific primers of Ref. [13], it was performed in a total volume of $25 \mu \mathrm{L}$ as described above. The cycling conditions were as follows: DNA polymerase activation $94{ }^{\circ} \mathrm{C}$ for $3 \mathrm{~min}$ followed by 30 cycles of amplification $\left(94^{\circ} \mathrm{C}\right.$ for $45 \mathrm{~s}, 55^{\circ} \mathrm{C}$ for $30 \mathrm{~s}$ and $72{ }^{\circ} \mathrm{C}$ for $90 \mathrm{~s}$ ) followed by $10 \mathrm{~min}$ at $72{ }^{\circ} \mathrm{C}$.

The PCR products were analysed on $2 \%$ agarose gel stained with Syber Safe (Invitrogen, USA). The DNA fragments were visualized by Omega Lum G instrument (Aplegen, USA). One hundred base-pair DNA ladder (Invitrogen, USA) was used to determine the size of the amplified fragments (amplicon 143, 460 and 1,044 bp) of M. haemolytica, P. multocida and P. multocida serogroup A, respectively.

\subsection{Histopathological Examination}

Ten percent NBF-fixed tissues were processed for histopathological examination according to standard methods. They were dehydrated in serial baths of alcohol and embedded in paraffin wax. Five micrometers-thick sections were stained with hematoxylin and eosin and examined under light microscope for histopahological changes.

\subsection{Mice Bioassay}

Identified strains were inoculated in BHI broth and incubated in a shaking incubator at $100 \mathrm{rpm}$ at $37^{\circ} \mathrm{C}$ overnight. The number of colony forming unit (CFU/mL) of inoculum was calculated by spread plate method in BHI agar plates [14]. Groups of five mice (one-month, male, average weight of $22 \mathrm{~g}$ ) were injected via the intra peritoneum. One group of mice was left as a control group and injected only with fresh BHI broth. Injected mice were observed for $24 \mathrm{~h}$ 
for the fatality rates. Liver and lung samples from the dead mice were streaked onto sheep blood agar and incubated as described above for bacterial isolation. Furthermore, colonies were confirmed by conventional PCR specific for M. haemolytica [11] and P. multocida [13].

\section{Results}

\subsection{Screening of Pasteurella Species Using RT-PCR}

The analysis of 162 samples from different species (sheep, bovine and goats) by RT-PCR showed that: 67 samples (41\%) were positive, namely 51 swabs $(76 \%)$ and 16 lungs (24\%). The distribution of samples by species and their results are presented in Table 1.

\subsection{Bacterial Isolation and PCR Confirmation}

A positive sample by RT-PCR was further confirmed using classic bacteriological and biochemical techniques. Gram-negative, catalase $(+)$, oxidase $(+)$ and distinct pink to red colonies on MacConkey agar were characteristic of $M$. haemolytica.

Confirmation of the bacterial colonies was done using conventional PCR. M. haemolytica was detected in 34 out of 67 strains examined. A total of 28 (55\%) strains were from nasal swabs and six (38\%) strains were from lungs (Table 2 and Fig. 2). The molecular identification of the 34 strains with the specific primers in sodA gene revealed positive amplification of $143 \mathrm{bp}$ fragment (Fig. 2).

Absence of bacterial growth MacConkey agar was characteristic of $P$. multocida, the confirmation was done using PCR gel based; nine samples (seven swabs and two lungs) were positive representing respectively $14 \%$ and $13 \%$ from all samples tested (Table 2, Figs. 3 and 4).

\subsection{Histopathological Findings}

Histopathological changes encountered in most lungs of examined animals included severe edema of the interlobular spaces and its infiltration with polymorphunulear (PMNs) and macrophages and fibrin

Table 1 Rate of isolation of Pasteurella from different species of animals suffering from respiratory distress and/or lesions.

\begin{tabular}{lllll}
\hline \multirow{2}{*}{ Types of samples } & Animals & Number of samples & & Number of positive \\
\cline { 4 - 5 } & Sheep & 75 & Number & Percentage (\%) \\
\hline \multirow{3}{*}{ Nasal swabs } & Goat & 6 & 26 & 35 \\
& Bovine & 40 & 3 & 50 \\
& Total & 121 & 22 & 55 \\
& Sheep & 4 & 51 & 42 \\
\hline \multirow{2}{*}{ Lung tissues } & Goat & 1 & 3 & 75 \\
& Bovine & 36 & 12 & 33 \\
& Total & 41 & 16 & 39 \\
\hline
\end{tabular}

Table 2 Rate of isolation of Mannheimia haemolytica and Pasteurella multocida from different species of isolated strains.

\begin{tabular}{lllllll}
\hline \multirow{2}{*}{ Types of samples } & Species & Number of samples & \multicolumn{2}{c}{$\begin{array}{c}\text { Number of positive } \\
(M . \text { haemolytica })\end{array}$} & $\begin{array}{c}\text { Number of positive } \\
(P . \text { multocida })\end{array}$ \\
\cline { 4 - 7 } & & & Number & Percentage (\%) & Number & Percentage (\%) \\
\hline \multirow{4}{*}{ Nasal swabs } & Sheep & 26 & 11 & 42 & 4 & 15 \\
& Goat & 3 & 3 & 100 & 0 & 0 \\
& Bovine & 22 & 14 & 64 & 3 & 14 \\
\hline \multirow{4}{*}{ Lung } & Total & 51 & 28 & 55 & 7 & 0 \\
& Sheep & 3 & 1 & 33 & 0 & 14 \\
& Goat & 1 & 1 & 100 & 0 & 17 \\
\hline
\end{tabular}




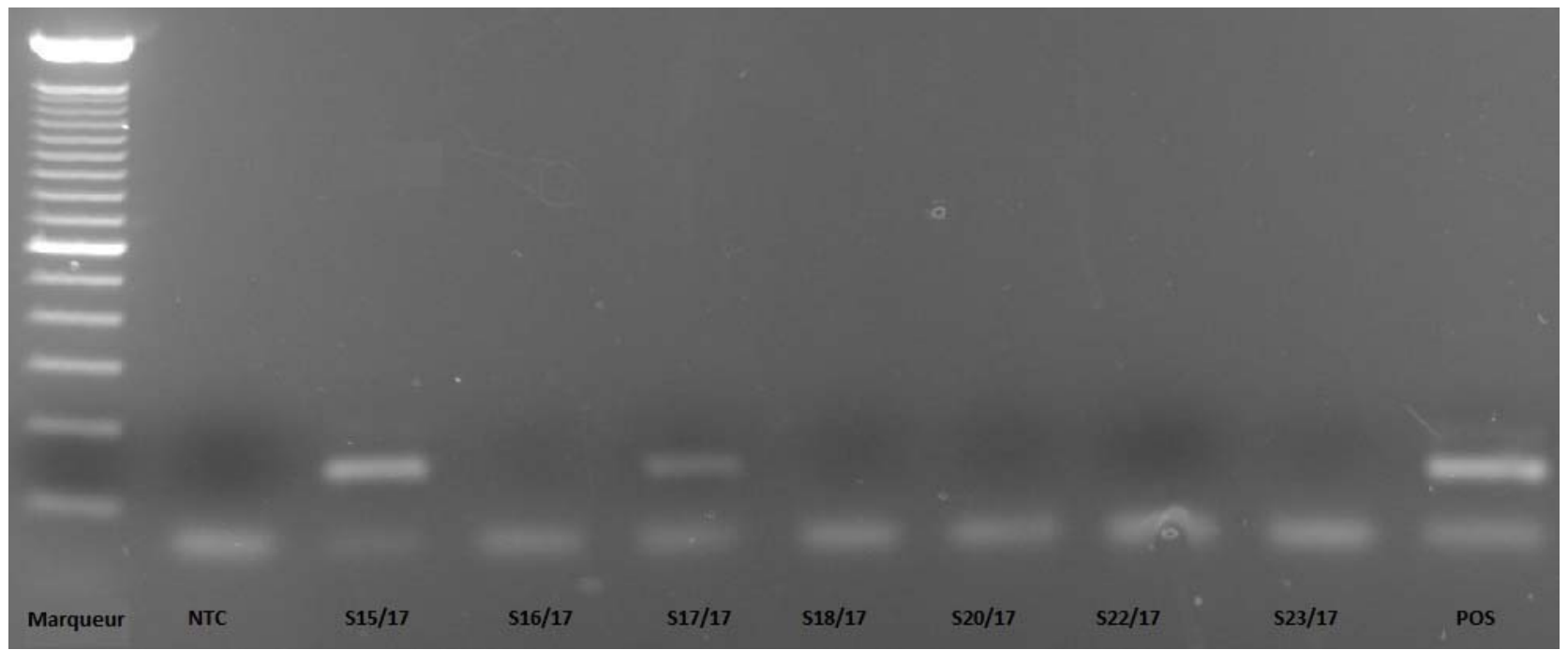

Fig. 2 Agarose gel electrophoresis showing amplification of 143 bp fragments specific for Mannheimia haemolytica.

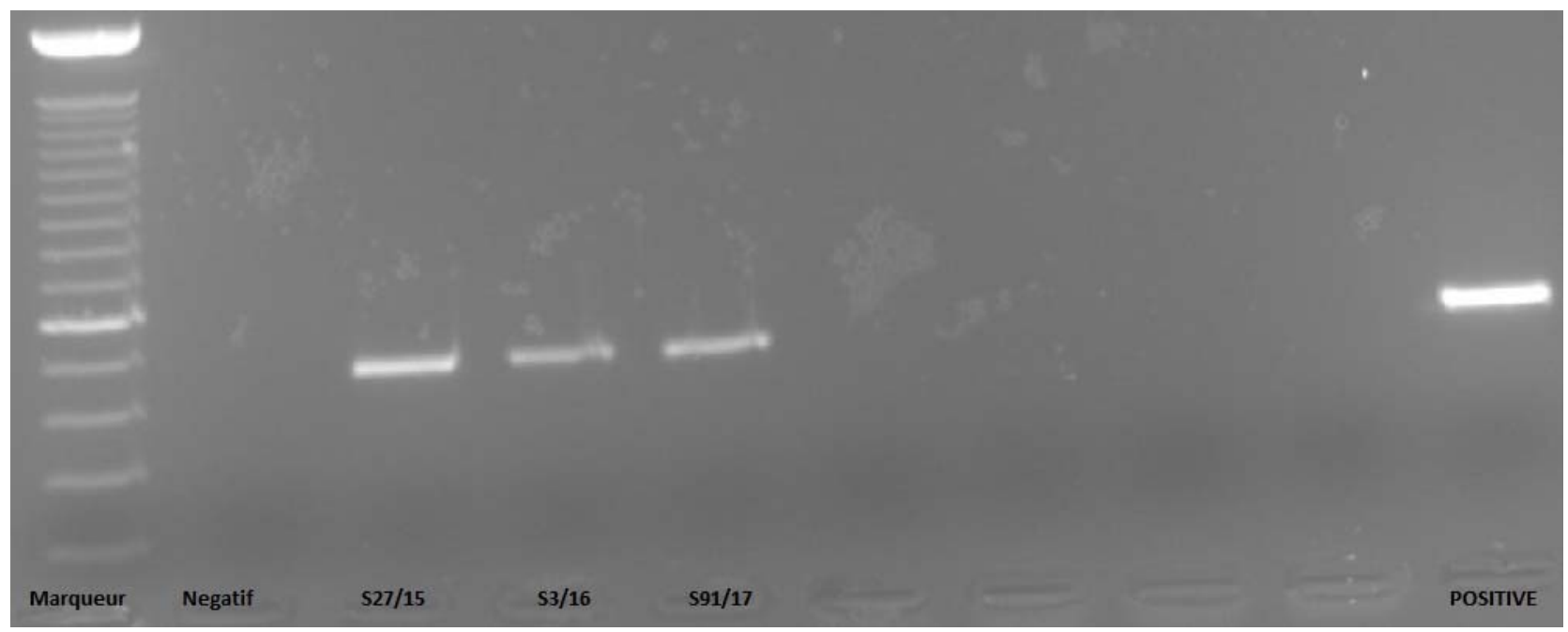

Fig. 3 Agarose gel electrophoresis showing amplification of $460 \mathrm{bp}$ fragments specific for Pasteurella multocida.

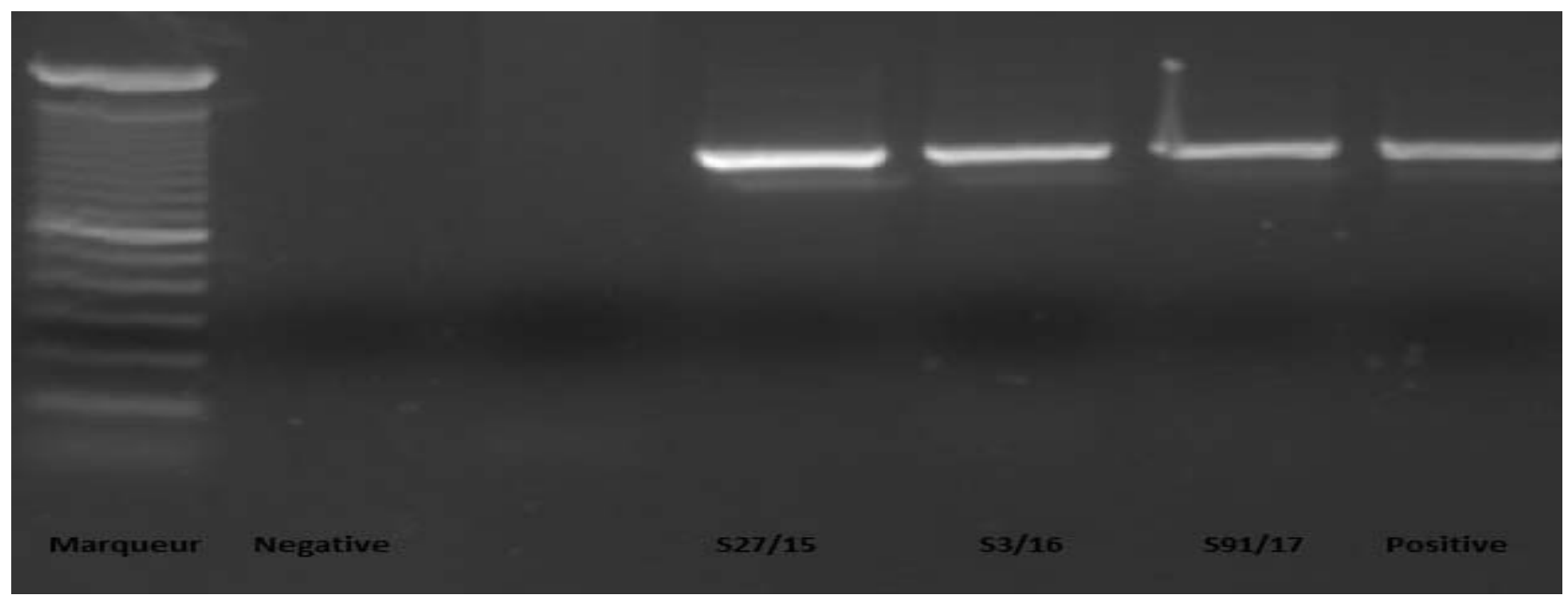

Fig. 4 Agarose gel electrophoresis showing amplification of 1,044 bp fragments specific for $P$. multocida serogroup A. 

Species from Ruminants in Six Different Regions in Morocco
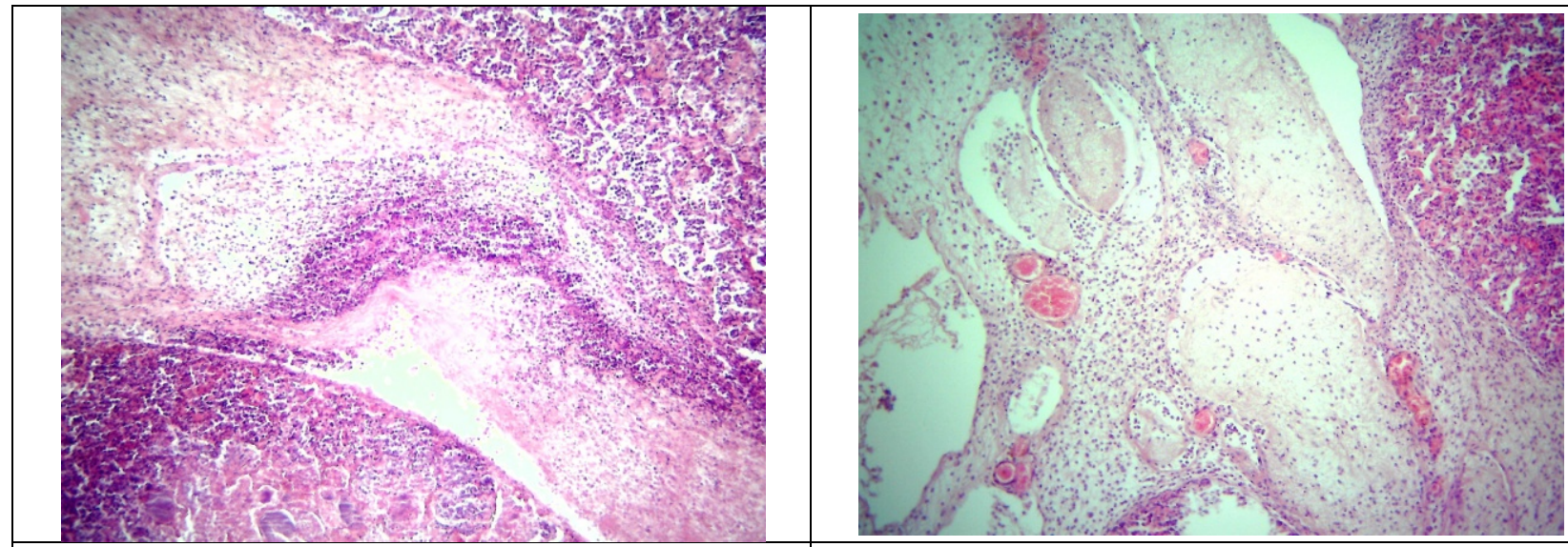

(a) Lung of calf-severe edema and fibrino-leucocytic infiltration (b) Lung of calf-edema and fibrino-leucocytic infiltration of of interlobular spaces. H \& E, $\times 10$. pulmonary pleural spaces. $\mathrm{H} \& \mathrm{E}, \times 10$.
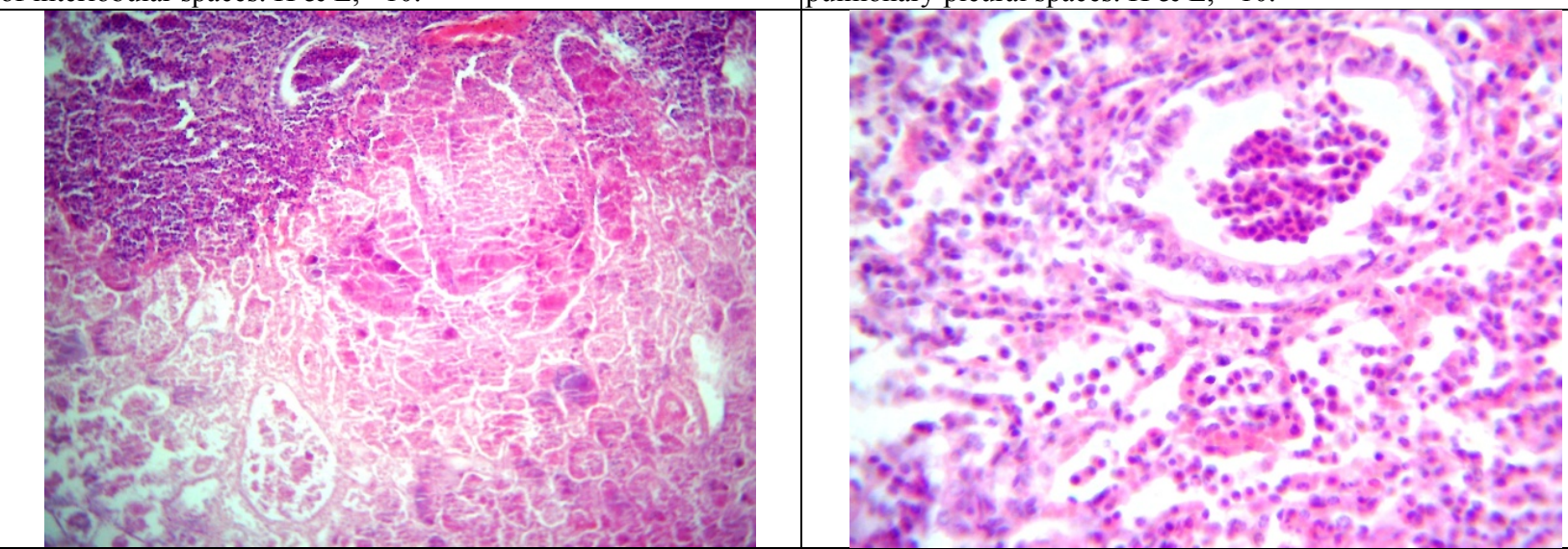

(c) Lung of calf-subacute leucocytic and necrotizing (d) Lung of calf-subacute leucocytic bronchopneumonia. Severe bronchopneumonia. Severe edema, hyperemia and leucocytic leucocytic infiltrate within alveolar spaces and secondary infiltrate within the lumen of alveolar spaces and bronchi and bronchus (arrow) $\mathrm{H} \& \mathrm{E}, \times 100$. severe pulmonary parencymal necrosis with the presence of bacterial colonies (arrows). $\mathrm{H} \& \mathrm{E}, \times 40$.

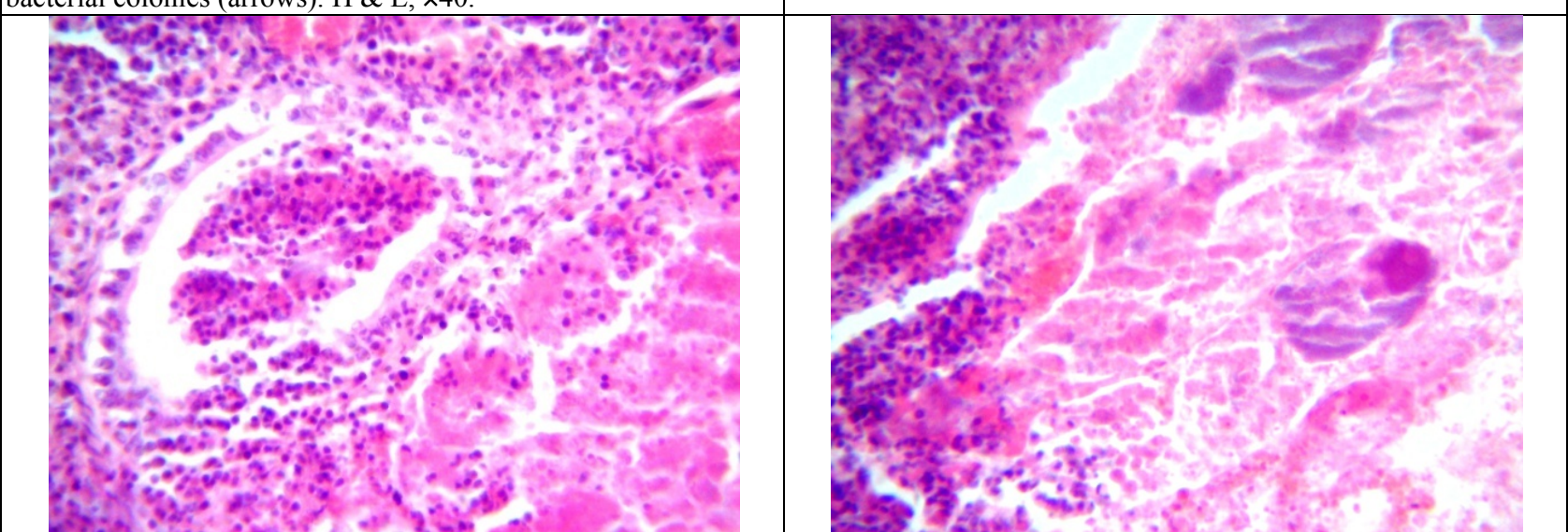

(e) Lung of calf-subacute leucocytic bronchopneumonia. Severe(f) Lung of calf-severe and diffuse leucocytic infiltrate and leucocytic infiltrate within alveolar spaces and secondary pulmonary parencymal necrosis $(\mathrm{P})$ with the presence of bacterial bronchus (arrow) and severe pulmonary parencymal necrosis (P). colonies (arrows). $\mathrm{H} \& \mathrm{E}, \times 100$.

$\mathrm{H} \& \mathrm{E}, \times 100$

Fig. 5 Histopathology microphotograph from lung. 
flames deposits (Figs. 5a and 5b). There was also a heavy PMNs and macrophages load of the bronchial lumen and alveolar spaces associated in some areas with multifocal and severe respiratory parenchymal necrosis (Figs. 5c and 5d). These changes were consistent with a diagnosis of very severe acute bronchopneumonia. In all cases, several bacterial colonies were identified in situ and appeared as dark blue granular rods (Figs. 5e and 5f).

\subsection{Mice Bioassay}

The study of pathogenicity of all Pasteurella strains isolated and identified showed that 26 strains caused a $100 \%$ mortality rate in mice within $12-18 \mathrm{~h}$, the other strains showed mortality rate greater than $60 \%$ within $19 \mathrm{~h}$ and $24 \mathrm{~h}$. Whereas, no mortality was recorded in all five mice used as control and injected with BHI broth culture even after $2 \mathrm{~d}$ post injection.

\section{Discussion}

High losses in animals with respiratory distress is not always associated with (primary) viral infections $[15,16]$. M. haemolytica and P. multocida are the important bacteria involved in respiratory infections as a primary or secondary pathogen associated with high fatality rate in ruminants [16].

In Morocco, scientific study data on respiratory diseases caused by Pasteurella are very scarce, except a few scattered data linked to intensive cattle breeding. Farmers and veterinarians often declare outbreaks of respiratory distress among cattle and sheep in the country and submission of field cases for diagnosis.

In the present study, investigations were conducted in six different regions of the Kingdom of Morocco in breeding animals with respiratory clinical signs such as high fever, nasal discharge, respiratory distress, polypnoea and death within few days [1]. In some areas, $100 \%$ of the collected samples were positive for bacterial involved in pasteurellosis disease in Oujda, Benslimane and Berrchid, and a minimum of $24 \%$ positive samples were recorded in a one region Laarache.

M. haemolytica was isolated and confirmed by PCR test in all farmes investigated. This bacteria was found in 34 out of 67 samples (51\%). This prevalence rate is higher than those described by Eshetu [17] and Nurhusein [18] with respective prevalence rates of $13 \%$ and $8.7 \%$. However, P. multocida was found only in nine out of 67 samples (13\%). PCR group and PCR for capsular type detection was found to be a rapid and sensitive method, as reported earlier by Townsend et al. [13] and Al-Maary et al. [19].

From the results obtained on the confirmation assay gel based PCR it clearly appears that $M$. hemolytica $51 \%$ is the dominant bacterium in all samples analysed in the six regions investigated versus $P$. multocida which represents only $13 \%$.

Among these, 43 strains induced a mortality rate greater than $50 \%$ in challenged mice. This observed pathogenicity rate shows that the isolated strains have major pathogenic power, which caused the death of inoculated mice in $24 \mathrm{~h}$. These findings are in accordance with histopathological changes consisting of severe acute bronchopneumonia shown in lung tissues collected from field affected animals either cattle or sheep. Such tissue changes were described in cattle infected with these bacteria by Zecchinon et al. [1] and Lopez [20].

\section{Conclusions}

This is the first study in Morocco, which reports the circulation of $M$. haemolytica in ruminants in the field. About $21 \%$ of samples collected from sick animals were positive. The bacteria were detected in samples obtained from six localities in Morocco indicating widespread epidemics. Isolates were highly pathogenic to mice. This study constitutes a crucial and a necessary step allowing preventive and veterinary medicine to support pasteurellosis disease controls in the country. 


\section{Acknowledgments}

Thank you very much for Dr. M. Chadli and for all of the people who collaborated in this study particularly the private veterinary for participating in samples collection and also many thanks to Abdellah Loudiyi (Biopharma animal house) \& Nazih (IAV animalhouse) for doing Mice bioassay.

\section{References}

[1] Zecchinon, L., Fett, T., and Desmecht, D. 2005. "How Mannheimia haemolytica Defeats Host Defence through a Kiss of Death Mechanism." Vet. Res. 36 (2): 133-56.

[2] Trevisan. 1887. "Taxonomy of the Genus Pasteurella." http://doi.namesforlife.com/10.1601/tx.3371.

[3] Confer, A. W. 2009. "Update on Bacterial Pathogenesis in BRD." Anim. Health Res. Rev. 10 (2): 145-8.

[4] Fulton, R. W. 2009. "Bovine Respiratory Disease Research (1983-2009).” Anim. Health Res. Rev. 10 (2): $131-9$.

[5] McVey, D. S. 2009. "BRD Research Needs in the Next 10-20 Years." Anim. Health Res. Rev. 10 (2): 165-7.

[6] Smith, G. R., and Philips, J. E. 1990. "Pasteurella and Actinobacillus." In Principales of Bacteriology, Virology and Immunology, 8th ed. Vol. 2. B. C. Decker Inc., USA, 383-99.

[7] Kishimoto, M., Tsuchiaka, S., Rahpaya, S. S., Hasebe, A., Otsu, K., and Sugimura, S. 2017. "Development of a One-Run Real-Time PCR Detection System for Pathogens Associated with Bovine Respiratory Disease Complex." J. Vet. Med. Sci. 79: 517-23.

[8] Gentry, M. J., Confer, A. W., and Craven, R. C. 1987. "Effect of Repeated in Vitro Transfer of Pasteurella haemolytica A1 on Encapsulation, Leukotoxin Production and Virulence.” J. Clin. Microbiol. 25: 142-5.

[9] Angen, O., Mutters, R., Caugant, D. A., Olsen, J. E., and Bisgaard, M. 1999. "Taxonomic Relationships of the Pasteurella haemolytica Complex as Evaluated by DNA-DNA Hybridizations and 16S rRNA Sequencing with Proposal of Mannheimia haemolytica gen. nov., comb, nov., Mannheimia granulomatis comb. nov., Mannheimia glucosida sp. nov., Mannheimia ruminalis sp. nov. and Mannheimia varigena sp. nov.” Int. J. Syst.
Bacteriol. 49: 67-86.

[10] Quinn, P. J., Carter, M. E., Markey, B., and Carter, G. R. 1994. "Bacterial Pathogens: Microscopy, Culture and Identification." In Clinical Veterinary Microbiology, edited by Sharma, S. N., and Adlakha, S. C. London, England: Wolfe Publishing.

[11] Guenther, S., Schierack, P., Grobbel, M., Lübke-Becker, A., Wieler, L. H., and Ewers, C. 2008. "Real-Time PCR Assay for the Detection of Species of the Genus Mannheimia." J. Microbiol. Methods 75: 75-80.

[12] Gautier, A. L., Dubois, D., Escande, F., Avril, J. L., Trieu-Cuot, P., and Gaillot, O. 2005. "Rapid and Accurate Identification of Human Isolates of Pasteurella and Related Species by Sequencing the SodA Gene." J. Clin. Microbiol. 43: 2307-14.

[13] Townsend, K. M., Boyce, J. D., Chung, J. Y., Frost, A. J., and Adler, B. 2001. "Genetic Organization of Pasteurella multocida cap Loci and Development of a Multiplex Capsular PCR Typing System.” J. Clin. Microbiol. 39: 924-9.

[14] Goldman, E., and Green, L. H. 2008. Practical Handbook of Microbiology, 2nd ed. Boca Raton, Florida: CRC Press.

[15] Grissett, G. P., White, B. J., and Larson, R. L. 2015. "Structured Literature Review of Responses of Cattle to Viral and Bacterial Pathogens Causing Bovine Respiratory Disease Complex.” J. Vet. Intern. Med. 29: 770-80.

[16] Panciera, R. J., and Confer, A. W. 2010. "Pathogenesis and Pathology of Bovine Pneumonia." Vet. Clin. North Am. Food Anim. Pract. 26 (2): 191-214.

[17] Eshetu, M. 1991. "Pneumonic Pasteurellosis in Sheep Slaughtered at Addis Ababa Abattoir." Debre-Zeit: DVM thesis, FVM, AAU.

[18] Nurhusein, Y. 2005. "Aerobic Bacterial Flora in the Respiratory Tract of Apparently Healty Sheep Slaughtered in Dessie Abattror." Debre-Zeit: DVM thesis, FVM, AAU.

[19] Al-Maary, K. S., Dawoud, T. M., Mubarak, A. S., Hessain, A. M., Galal, H. M., and Kabli, S. A. 2017. "Molecular Characterization of the Capsular Antigens of Pasteurella multocida Isolates Using Multiplex PCR." Saudi J. Biol. Sci. 24: 367-70.

[20] Lopez, A. 2001. "Respiratory System, Thoracic Cavity and Pleura." In Thomson's Special Veterinary Pathology. Mosby Inc., USA, 125-96. 